\title{
MODELING PRICING AND SCHEDULING STRATEGIES FOR AIR CARGO CARRIERS AS NON-COOPERATIVE GAMES
}

Oliver Feng-Yeu Shyr

Department of Urban Planning, National Cheng Kung University, Tainan, Taiwan, R.O.C., ofshyr@mail.ncku.edu.tw

Yuan-Lu Lee

Evergreen International Corp., Taiwan, R.O.C.

Follow this and additional works at: https://jmstt.ntou.edu.tw/journal

Part of the Management Information Systems Commons

\section{Recommended Citation}

Shyr, Oliver Feng-Yeu and Lee, Yuan-Lu (2012) "MODELING PRICING AND SCHEDULING STRATEGIES FOR AIR CARGO CARRIERS AS NON-COOPERATIVE GAMES," Journal of Marine Science and Technology. Vol. 20: Iss. 2, Article 13. DOI: $10.51400 / 2709-6998.1841$

Available at: https://jmstt.ntou.edu.tw/journal/vol20/iss2/13

This Research Article is brought to you for free and open access by Journal of Marine Science and Technology. It has been accepted for inclusion in Journal of Marine Science and Technology by an authorized editor of Journal of Marine Science and Technology. 


\title{
MODELING PRICING AND SCHEDULING STRATEGIES FOR AIR CARGO CARRIERS AS NON-COOPERATIVE GAMES
}

\author{
Oliver Feng-Yeu Shyr ${ }^{1}$ and Yuan-Lu Lee ${ }^{2}$
}

Key words: cargo carrier, pricing and scheduling, Nash equilibrium, non-cooperative game.

\begin{abstract}
To develop efficient pricing and service strategies for air cargo carriers, we formulated air cargo demand as a Multinomial Logit model to reveal forwarders' preferences toward freightage, flight frequency and service reliability. By applying non-cooperative game approach, we solve the market equilibrium to produce optimal freightage of priority and ordinary cargo for forwarders with various shipping volumes as well as the optimal flight schedules of air cargo carriers. In the case study, we found that the leader of air carriers would have not only the largest share, but also the highest freightage for both ordinary and priority cargo. And, with the provision of transfer flights, carriers could further reduce their operating cost by $1 \%$ to $3 \%$.
\end{abstract}

\section{BACKGROUND}

In recent years, the percentage of cargo being shipped by air carriers has been increased significantly. According to the business report presented by Airbus' head of freighter marketing Lenormand [4], the air freight between North America and East Asia is one of the fast growing markets in the world. By 2023, its market share will hit $26.15 \%$, making it the biggest market in the world. On the other hand, the high market concentration ratio suggests that air cargo service is an oligopolistic market in transport industry. As a result, the efficiency of service network and pricing strategy are the major factors affecting the performance of air cargo carriers. Because of the vigorous competition in the market, air cargo carriers are keen to maintain or raise their market shares. The strategies taken include freightage discount for frequent users and increasing flight frequency for priority goods by using

Paper submitted 06/23/09; revised 04/26/10; accepted 01/11/11. Author for correspondence: Oliver Feng-Yeu Shyr (e-mail: ofshyr@mail.ncku.edu.tw).

${ }^{I}$ Department of Urban Planning, National Cheng Kung University, Tainan, Taiwan, R.O.C.

${ }^{2}$ Evergreen International Corp., Taiwan, R.O.C. available cargo spaces in passenger flights.

Most of the recent studies focused on either the pricing strategy or the scheduling efficiency of air freight transport. For example, Xiao and Yang [16] apply non-cooperative game among shippers, carriers and infrastructure companies (IC) to explore the competitive equilibrium in an oligopolistic market in a freight network. They assume that all three kinds of players act as profit maximizing agents given that the carriers and ICs would behave cooperatively in their own coalitions. By using a three-stage game-theoretic model, they show that the equilibrium flows can also maximize total system profits if the IC and the carrier both use vertically efficient nonlinear pricing schedules. A multi-market oligopoly model was employed by Zhang and Zhang [19] to examine the effect of cargo liberalization on competition between all-cargo carriers and mixed passenger/cargo carriers. They find that if home carriers engage in the joint production of cargo and passenger services, whereas foreign carriers produce the two outputs separately, then unilateral cargo liberalization by the home country will reduce home firm profits and increase foreign profits, and raise air fares for passenger travel when foreign competition in the passenger sector is limited. They suggested that the separation of air cargo and passenger flights might be fraught with difficulty in Asia due to the characteristics of its air cargo market, in which most passenger carriers have substantial cargo businesses and operate "combi" fleets.

As for the scheduling problem, Yan, et al. [17] use timespace network techniques to formulate the models which deal with the scheduling problems of international express carriers to meet the new variable demands in real time. To efficiently solve their models, an algorithm is developed with the assistance of mathematical programming solver, CPLEX. Tang, et al. [14] developed an integrated scheduling model that combines passenger, cargo and "combi" flight scheduling. They employed network flow techniques to construct the model which is formulated as an integer multiple commodity network flow problem that is characterized as NP-hard. A family of heuristics, based on Lagrangian relaxation, a sub-gradient method, heuristics for the upper bound solution, and a flow decomposition algorithm, was developed to solve the model. Their test results, mainly using data from a major Taiwan airline's operations, show the good performance of the model 
and the solution algorithms.

There were also papers that dealt with the nature of the market and the pricing strategy in general. Bowen and Leinbach [2] stated that a rapid increase in the level of market concentration in supply chain industries has created firms that enjoy the economies of scale and scope necessary to offer multinational clients integrated services on a worldwide basis. Their paper examines how changes in the structure of the freight forwarding industry have affected the nature of the services. They used data from interviews with over 100 freight forwarders in Singapore, Malaysia, and the Philippines to examine both the geographic variation in the provision of air cargo services and the manner in which the types of services a forwarder offers vary with firm size. Park, et al. [9] explore the relative importance of factors that influence the adoption of air express delivery service, and evaluates the competitiveness of air cargo express carriers in the Korean market. They applied AHP analysis to show that accuracy and promptness are the two most influential factors for competitiveness. Smith et al. [13] demonstrate the development, testing and application of statistical models to study actual billings (net of discounts) for expedited freight services. Their models reveal the structure of net tariffs so that carriers can identify customers and terminals whose revenues are deficient. And their models show situations where business activities, pricing structures or negotiated discounts need review and verify that the overwhelming determinants of monthly charges to shippers are the fundamental cost drivers for the industry. Zhang, et al. [18] examined the effect of multimodal integration on the rivalry between two transport chains - a forwarder-airline alliance and an integrator - under the economies of traffic density. An improvement in multimodal integration by a forwarder-airline alliance would increase the alliance's output, while reducing the integrator's output, not only in the multimodal market but also in other markets of the cargo network. It would further increase the alliance's profit, provided the intermodal improvement is not too costly, while reducing the integrator's profit, and would likely improve both consumer surplus and total surplus. We also find that an alliance in general leads to greater market shares for the firms involved than outsourcing.

To incorporate the oligopolistic competition behavior into the scheduling problem of all the carriers in the market, we propose a three-stage framework. For stage one, we formulated and calibrated the payoff functions of air cargo carriers. The payoff functions were partitioned into two parts, i.e., the revenues derived from forwarders' demand, and the costs for the services. The demand was formulated as a Logit function to reveal forwarders' preferences toward freightage, flight frequency and service reliability. And the cost function was formulated by information provided by Oum and $\mathrm{Yu}$ [5]. For stage two, we applied non-cooperative game approach, i.e., the Bertrand model, to solve the optimal pricing strategies for variable O-D demands under oligopoly market structure. For stage three, we find the optimal flight frequency by solving cost minimization scheduling problem using the predicted demand from stage two and repeat stage two with new flight schedule. We stop the iterations if the variation of the freightage solved from two consecutive iterations in stage two is small or the number of iterations exceeds our limit.

Inspired by Lenormand's report, we demonstrated our case study by using data based on the air cargo market of Taipei to US West Coast served by three major cargo carriers, i.e., China Airlines (CAL), EVA Airways and Northwest Airlines. We calibrated the cargo demand by using SP and RP survey data from a stratified sampling of forwarders. Then by using the iterative feedback approach, we solve the problem of a non-linear mixed-integer system of equations that produces the optimal freightage and the flight schedule of these air cargo carriers.

\section{MODEL FORMULATION}

To start with the non-cooperative game among air cargo carriers, we need to formulate the payoff functions [3], i.e., the revenues and the costs as functions of freightage, flight frequency, and service reliability, for these carriers. These models were formulated based on the studies by Hansen [2], Nicole [4], Shyr and Chang [10], Shyr and Hung [11], and Shyr and Kuo [12], and were described in the following subsections. Table 1 shows the list of variables in the following content.

\section{The Payoffs of Air Cargo Carriers}

Because the freightage of air cargo might vary from one good to another, we focused on the freightage for two types of services: ordinary and priority. Usually, the priority cargo could be transported by passenger flights if the cargo space was available or the schedule of cargo flights did not meet the requirement of delivery. The ordinary cargo, on the other hand, would be transported primarily by cargo flights.

As shown in Eq. (1), the payoff of air cargo carrier $k$ was partitioned into three parts, i.e., the revenue from ordinary cargo, the revenue from priority cargo, and the costs of airfreight services. That is,

$$
\pi^{k}=\sum_{i j \in L^{k}}\left(T R_{i j}^{k 1}+T R_{i j}^{k 2}-T C_{i j}^{k}\right)
$$

For the segment $i j$, the revenue from the ordinary and the priority cargo was formulated as follows:

$$
\begin{gathered}
T R_{i j}^{k m}=\sum_{l} O F_{i j}^{k l m} \times q_{i j}^{k l m} \quad m=1,2 \\
q_{i j}^{k l m}=Q_{i j}^{l m} \times P_{i j}^{k l m} \quad m=1,2
\end{gathered}
$$

\section{The Demands of Air Cargo from Forwarders}

Followed by Section 2.1, the share of air cargo from forwarder $l$ to carrier $k$ of OD pair $i j$ as shown in Eq. (4) was 
Table 1. List of symbols and notations (in the order of appearance).

\begin{tabular}{|c|c|}
\hline notations & description \\
\hline$\pi^{k}$ & payoff function of air cargo carrier $k$ \\
\hline$T R_{i j}^{k m}$ & $\begin{array}{l}\text { revenue from ordinary }(m=1) \text { and priority }(m=2) \\
\text { cargo of carrier } k \text { of OD pair } i j\end{array}$ \\
\hline$T C_{i j}^{k}$ & costs of air cargo services of carrier $k$ of OD pair $i j$ \\
\hline$L^{k}$ & set of service network of carrier $k$ \\
\hline$O F_{i j}^{k l m}$ & $\begin{array}{l}\text { ordinary }(m=1) \text { and priority }(m=2) \text { freightage for } \\
\text { forwarder } l \text { offered by carrier } k \text { of OD pair } i j\end{array}$ \\
\hline$q_{i j}^{k l m}$ & $\begin{array}{l}\text { demand of ordinary }(m=1) \text { and priority }(m=2) \text { air } \\
\text { cargo from forwarder } l \text { to carrier } k \text { of OD pair } i j\end{array}$ \\
\hline$Q_{i j}^{l m}$ & total demand from forwarder $l$ of OD pair $i j$ \\
\hline$P_{i j}^{k l m}$ & $\begin{array}{l}\text { share of type } m \text { cargo from forwarder } l \text { to carrier } k \text { of } \\
\text { OD pair } i j\end{array}$ \\
\hline$V_{i j}^{k l m}$ & $\begin{array}{l}\text { utility function of forwarder } l \text { choosing carrier } k \text { for } \\
\text { type } m \text { cargo of OD pair } i j\end{array}$ \\
\hline$X_{i j}^{k l m}$ & $\begin{array}{l}\text { service attributes such as freightage, flight frequency, } \\
\text { and service reliability provided by carrier } k \text { to for- } \\
\text { warder } l \text { for type } m \text { cargo of OD pair } i j \text { in the utility } \\
\text { function }\end{array}$ \\
\hline$\alpha_{i j}^{k m}$ & carrier specific constant in the utility function \\
\hline$\beta_{i j}^{m}$ & vector of coefficients in the utility function \\
\hline$T^{h}$ & fixed cost of aircraft type $h$ \\
\hline$\lambda^{h}$ & variable cost of aircraft type $h$ \\
\hline$d_{a}$ & flight distance of segment $a$ \\
\hline$\phi_{i j}$ & flight frequency of OD pair $i j$ \\
\hline$\delta_{a}^{i j}$ & $\begin{array}{l}\text { dummy variable, } 1 \text { if OD pair } i j \text { was included on } \\
\text { segment } a\end{array}$ \\
\hline$y_{i j}^{h}$ & $\begin{array}{l}\text { dummy variable, } 1 \text { if OD pair } i j \text { was served by aircraft } \\
\text { type } h\end{array}$ \\
\hline $\operatorname{Cap}_{a}^{h}$ & capacity of aircraft type $h$ on flight segment $a$ \\
\hline$F_{i j a}^{k}$ & cargo volume on flight segment $a$ for carrier $k$ \\
\hline$A^{k}$ & set of flight segment for carrier $k$ \\
\hline$H^{k}$ & set of aircraft types for carrier $k$ \\
\hline
\end{tabular}

formulated based on a discrete choice model derived by BenAkiva and Lerman [1]. Furthermore, the utility function of forwarder $l$ choosing carrier $k$ for type $m$ cargo of OD pair $i j$ was formulated as a linear function of freightage, flight frequency and service reliability as shown in Eq. (5). The linear utility is a commonly used functional form in previous studies by Shyr and Chang [10], Shyr and Hung [11], and Shyr and Kuo [12].

$$
\begin{gathered}
P_{i j}^{k l m}=\frac{e^{V_{i j}^{k l m}}}{\sum_{k=1}^{K} e^{V_{i j}^{k l m}}} m=1,2 \\
V_{i j}^{k l m}=\alpha_{i j}^{k m}+X_{i j}^{k l m} \beta_{i j}^{m}
\end{gathered}
$$

The form of our payoff function is nonlinear resulted from the logistic demand function embedded in Eq. (4). Similar forms have been used in the previous studies by Shyr and Chang [10], Shyr and Hung [11], and Shyr and Kuo [12]. In fact, our payoff function is a bell-shape, or quasi-concave function as shown in these studies.

\section{The Costs of Air Cargo Services}

According to Lenormand's statement, the importance of passenger aircrafts in air freight will decrease. In other word, his statement implies that to cope with the rapidly increasing and competing air cargo market, most of the carrier will rely more on the all-cargo or "combi" fleets than on the passenger flights. But due to our limitation on collecting the cost data from the "combi" fleets, our study would only focus on the scheduling of all-cargo flights. Thus, we formulated the costs of air cargo services as follows:

$$
T C^{k}=\sum_{i j \in L^{k}}\left[\sum_{h \in H} \sum_{a \in A}\left(T^{h}+\lambda^{h} d_{a}\right) \delta_{a}^{i j} y_{i j}^{h}\right] \phi_{i j}
$$

Subject to:

$$
\begin{gathered}
\sum_{h} \operatorname{Cap}_{a}^{h} \phi_{i j} \delta_{a}^{i j} y_{i j}^{h} \geq F_{i j a}^{k} \quad \forall i j \in L^{k}, a \in A^{k} \\
\delta_{a}^{i j} \in \text { Binary } \quad \forall i j \in L^{k}, a \in A^{k} \\
\sum_{h} y_{i j}^{h}=1 \quad \forall i j \in L^{k} \\
y_{i j}^{h} \in \text { Binary } \quad \forall i j \in L^{k}, h \in H^{k} \\
\phi_{i j} \geq 0 \quad \forall i j \in L^{k}
\end{gathered}
$$

Eq. (7) described the capacity constraint of the network.

\section{SOLUTION APPROACH}

Given the payoff functions in section 2, we solved the market equilibrium by applying MATHEMATICA, software developed by Varian [11]. The solution concept for the noncooperative game price competition approach was derived from Owen [6] and Hansen [2]. The procedures of the heuristic approach for the mixed integer optimization problem are summarized as follows:

Step 1: Calibrate the demand and cost model parameters formulated in section 2;

Step 2: Formulate the system of equations for the first order condition of payoff function with respect to the freightage of airline carriers;

Step 3: Solve the system of equations in Step 2 and find the freightage under current flight frequency;

Step 4: Compute the predicted demand and market shares with the freightage solved from Step 3; 
Table 2. Distribution of sample from various forwarders.

\begin{tabular}{|c|c|c|c|}
\hline scale of firm & tonnage & sample size & percentage \\
\hline \multirow{2}{*}{$\begin{array}{c}\text { annual shipment } \\
\text { in } 2004\end{array}$} & $<600$ & 5 & $12.5 \%$ \\
\cline { 2 - 4 } & $600 \sim 1200$ & 23 & $57.5 \%$ \\
\hline \multirow{2}{*}{$\begin{array}{c}>1200 \\
\text { employee \& }\end{array}$} & $\begin{array}{c}>50 \text { persons } \\
>8 \text { millions }\end{array}$ & 12 & $30 \%$ \\
\cline { 2 - 4 } operating capital & $\begin{array}{c}\leqq 50 \text { persons } \\
\text { 8 millions }\end{array}$ & 25 & $37.5 \%$ \\
\hline
\end{tabular}

Table 3. Factor loadings of carriers' service attributes.

\begin{tabular}{|l|c|c|}
\hline \multicolumn{1}{|c|}{ service attributes } & factor 1 & factor 2 \\
\hline reputation of reliable service & $\mathbf{0 . 8 1 0}$ & 0.000 \\
\hline on-time delivery & $\mathbf{0 . 5 9 8}$ & 0.105 \\
\hline security and safety & $\mathbf{0 . 6 0 8}$ & 0.529 \\
\hline tracking system of shipment & $\mathbf{0 . 7 9 5}$ & 0.367 \\
\hline service attitudes & $\mathbf{0 . 7 8 9}$ & 0.291 \\
\hline responsive to emergency & $\mathbf{0 . 8 6 0}$ & 0.257 \\
\hline aircraft maintenance & $\mathbf{0 . 7 8 7}$ & 0.119 \\
\hline violation of shipping guidance & 0.000 & $\mathbf{0 . 9 2 5}$ \\
\hline damage claim service & 0.294 & $\mathbf{0 . 8 1 2}$ \\
\hline reasonable freightage \& frequency & 0.306 & $\mathbf{0 . 8 4 6}$ \\
\hline
\end{tabular}

Step 5: Find the optimal flight frequency by solving cost minimization scheduling problem using the predicted demand from Step 4;

Step 6: Repeat Step 3 with new flight schedule solved from Step 5, and stop iteration if the variation of the freightage solved from Step 3 is within $1 \%$, or if the number of iterations exceeds 100 .

\section{CASE STUDY}

To calibrate the air cargo demand and the payoff function, we design both stated preference and revealed preference questionnaire for forwarders who have shipping demand from Taiwan to the west coast of North America. From Table 2 we found that most of our questionnaires are returned from medium-size forwarders. In the revealed preference data, we collect the information regarding the annual shipment delivered by three air cargo carriers, as well as freightage, delivery time, and service quality of these carriers. In the stated preference data, we have forwarders' choices of carriers under various scenarios of weekly flight frequency, freightage, and delivery time.

As for the questions regarding to service quality, we have forwarders' ratings of ten attributes, as shown in Table 3, ranging from 1 for very poor to 5 for very good. Table 3 also shows the factor loadings of these attributes in two major factors. From Table 3 we learned that factor 1 represents service quality on reliability and efficiency; while factor 2 represents service quality on responsibility and cost-effectiveness. The
Table 4. Factor scores of carriers' service attributes.

\begin{tabular}{|c|c|c|c|c|}
\hline \multirow{2}{*}{ farrier } & \multicolumn{2}{|c|}{ factor 1} & \multicolumn{2}{c|}{ factor 2 } \\
\cline { 2 - 5 } & mean & $\begin{array}{c}\text { standard } \\
\text { deviation }\end{array}$ & mean & $\begin{array}{c}\text { standard } \\
\text { deviation }\end{array}$ \\
\hline CAL & 23.145 & 3.2318 & 18.594 & 2.6346 \\
\hline EVA & 23.572 & 2.1148 & 18.538 & 1.6453 \\
\hline Northwest & 20.388 & 2.4264 & 15.886 & 2.0670 \\
\hline
\end{tabular}

Note: CAL as China Airline, and EVA as EVA Air.

Table 5. Model parameters for ordinary cargo: Taiwan to the west coast of North America. ( $t$ values shown in the parentheses)

\begin{tabular}{|l|c|c|}
\hline \multicolumn{1}{|c|}{ variables } & HVF & MLVF \\
\hline CAL constant & $\begin{array}{c}0.8863 \\
(3.2045)\end{array}$ & $\begin{array}{c}0.8160 \\
(3.9050)\end{array}$ \\
\hline \multirow{2}{*}{ EVA constant } & $\begin{array}{c}0.4933 \\
(1.3021)\end{array}$ & $\begin{array}{c}0.5684 \\
(2.6610)\end{array}$ \\
\hline \multirow{2}{*}{ freightage (NTD/kg) } & $\begin{array}{c}-0.0410 \\
(-11.234)\end{array}$ & $\begin{array}{c}-0.0621 \\
(-13.251)\end{array}$ \\
\hline \multirow{2}{*}{ weekly flight frequency } & 0.1034 & 0.0935 \\
& $(3.3877)$ & $(3.3868)$ \\
\hline \multirow{2}{*}{ mean delivery time (hour) } & -0.0093 & -0.0073 \\
& $(-3.4100)$ & $(-3.2708)$ \\
\hline \multirow{2}{*}{ service quality: factor 1} & 0.0724 & 0.0924 \\
\hline \multirow{2}{*}{ service quality: factor 2} & $(2.4502)$ & $(2.9502)$ \\
\hline $\mathrm{L}(\beta)$ & 0.0062 & 0.0034 \\
\hline $\mathrm{L}(0)$ & $(0.1205)$ & $(0.1324)$ \\
\hline$\rho^{2}$ & -543.93 & -952.62 \\
\hline \% of correct prediction & -701.34 & -1238.31 \\
\hline
\end{tabular}

Note: NTD as New Taiwan Dollar, 1 US Dollar $=32$ NTD.

overall rankings as shown in Table 4 suggest that carriers' service quality is between fair and very good. Among them, EVA Air receives the highest ranking in both factors.

The calibrated parameters of the market share models are shown in Table 5 for ordinary cargo and Table 6 for priority cargo. The models are estimated separately by two sample groups, i.e., the high-volume forwarders (HVF) and mediumto-low-volume forwarders (MLVF).

From Table 5 and Table 6 we found that the signs of the parameters are consistent with $a$ prioi, i.e., the negative signs for freightage and delivery time, the positive signs for flight frequency and service quality. Most of the t-values of these parameters are significant, except for the coefficients of service quality. In other words, forwarders are more sensitive to freightage, delivery time, and frequency rather than service quality. In addition, the IIA (Independent of Irrelevant Alternatives) test suggests that the market share model is consistent with the assumption of Multinomial Logit (MNL). 
Table 6. Model parameters for priority cargo: Taiwan to the west coast of North America. ( $t$ values shown in the parentheses)

\begin{tabular}{|l|c|c|}
\hline \multicolumn{1}{|c|}{ variables } & HVF & MLVF \\
\hline \multirow{2}{*}{ CAL constant } & $\begin{array}{c}0.0444 \\
(1.445)\end{array}$ & $\begin{array}{c}0.0566 \\
(1.263)\end{array}$ \\
\hline \multirow{2}{*}{ EVA constant } & $\begin{array}{c}0.1299 \\
(1.2785)\end{array}$ & $\begin{array}{c}-0.1754 \\
(-0.9011)\end{array}$ \\
\hline \multirow{2}{*}{ freightage (NTD/kg) } & -0.0363 & -0.055 \\
& $(-7.0440)$ & $(-8.1730)$ \\
\hline \multirow{2}{*}{ weekly flight frequency } & 0.2122 & 0.1914 \\
& $(5.8190)$ & $(4.9186)$ \\
\hline \multirow{2}{*}{ service quality: factor 1 } & 0.0464 & 0.0394 \\
& $(0.8902)$ & $(0.9314)$ \\
\hline \multirow{2}{*}{ service quality: factor 2 } & 0.0004 & 0.0009 \\
\hline $\mathrm{L}(\beta)$ & $(0.0624)$ & $(0.0148)$ \\
\hline $\mathrm{L}(0)$ & -329.47 & -488.21 \\
\hline$\rho^{2}$ & -404.53 & -620.23 \\
\hline$\%$ of correct prediction & 0.19 & 0.21 \\
\hline
\end{tabular}

Table 7. Operating cost of three air cargo carriers.

\begin{tabular}{|c|c|c|c|c|}
\hline carrier & aircraft & $\begin{array}{c}\text { loading } \\
\text { capacity (lb) }\end{array}$ & $\begin{array}{c}\text { fixed cost } \\
\text { (USD) }\end{array}$ & $\begin{array}{c}\text { variable cost } \\
\text { (USD/mile) }\end{array}$ \\
\hline CAL & B747-400F & 255,000 & 4352 & 23.22 \\
\hline EVA & MD-11F & 192,240 & 3076 & 16.97 \\
\hline \multirow{2}{*}{ Northwest } & DC10-10F & 135,300 & 2068 & 12.19 \\
\cline { 2 - 5 } & DC10-30CF & 177,400 & 2968 & 13.44 \\
\hline
\end{tabular}

Table 8. Weekly flights from Taiwan to the west coast of North America.

\begin{tabular}{|c|l|c|c|}
\hline carrier & \multicolumn{1}{|c|}{ route } & distance $(\mathrm{km})$ & frequency \\
\hline \multirow{4}{*}{ CAL } & TPE - LAX & 11,445 & 4 \\
\cline { 2 - 4 } & TPE - ANC - LAX & 11,299 & 2 \\
\cline { 2 - 4 } & TPE - ANC - SFO & 10,771 & 1 \\
\cline { 2 - 4 } & TPE - NRT - ANC & 7,306 & 1 \\
\hline \multirow{5}{*}{ EVA } & TPE - LAX & 11,445 & 4 \\
\cline { 2 - 4 } & TPE - ANC - LAX & 11,299 & 2 \\
\cline { 2 - 4 } & TPE - ANC - SFO & 10,771 & 1 \\
\cline { 2 - 4 } & TPE - NRT - ANC & 7,306 & 1 \\
\hline \multirow{4}{*}{ Northwest } & TPE - NRT - ANC - SFO & 11,482 & 2 \\
\cline { 2 - 4 } & TPE - NRT - ANC - LAX & 11,882 & 1 \\
\cline { 2 - 4 } & TPE - NRT - ANC & 7,306 & 1 \\
\hline
\end{tabular}

Note: codes of airports, ANC as Anchorage, AK, LAX as Los Angles, NRT as Tokyo Narita, SFO as San Francisco, and TPE as Taipei.

The cost and flight data of three carriers as shown in Tables 7 and 8 reveal the fact that CAL has the largest shipping capacity while the Northwest Airline has the oldest fleet with
Table 9. Freightage structure of three cargo carriers.

\begin{tabular}{|l|c|c|c|}
\hline \multicolumn{1}{|c|}{ carrier } & CAL & EVA & Northwest \\
\hline ordinary cargo (NTD/kg) & $80 \sim 100$ & $80 \sim 100$ & $70 \sim 90$ \\
\hline priority cargo (NTD/kg) & $85 \sim 105$ & $85 \sim 105$ & $75 \sim 95$ \\
\hline weekly cargo flights & 8 & 8 & 4 \\
\hline weekly passenger flights & 6 & 6 & 4 \\
\hline delivery time (hour) & 18 & 18 & 36 \\
\hline
\end{tabular}

Table 10. Optimal freightage and shipment of priority cargo.

\begin{tabular}{|c|l|c|c|}
\hline \multirow{2}{*}{ carrier } & forwarder type & HVF & MLVF \\
\cline { 2 - 4 } & total tonnage & 1500 & 100 \\
\hline \multirow{3}{*}{ CAL } & shipment (tons) & 724.8 & 58 \\
\cline { 2 - 4 } & freightage (NTD/kg) & 77.2 & 82.6 \\
\cline { 2 - 4 } & profits (NTD) & $46,801,065$ & $4,801,285$ \\
\hline \multirow{3}{*}{ EVA } & shipment (tons) & 606.2 & 30 \\
\cline { 2 - 4 } & freightage (NTD/kg) & 74.4 & 80.6 \\
\cline { 2 - 4 } & profits (NTD) & $53,897,469$ & $2,364,861$ \\
\hline \multirow{3}{*}{ Northwest } & shipment (tons) & 169.0 & 12 \\
\cline { 2 - 4 } & freightage (NTD/kg) & 64.1 & 71.0 \\
\cline { 2 - 4 } & profits (NTD) & $10,833,620$ & 837,830 \\
\hline
\end{tabular}

Table 11. Optimal freightage and shipment of ordinary cargo.

\begin{tabular}{|c|l|c|c|}
\hline \multirow{3}{*}{ carrier } & \multicolumn{1}{|c|}{ forwarder type } & HVF & MLVF \\
\cline { 2 - 4 } & total tonnage & 73,500 & 4,900 \\
\hline \multirow{4}{*}{ CAL } & shipment (tons) & 38,497 & 2,107 \\
\cline { 2 - 4 } & freightage: (NTD/kg) & 70.4 & 75.2 \\
\cline { 2 - 4 } & profits (NTD) & $388,731,891$ & $160,833,090$ \\
\hline \multirow{3}{*}{ EVA } & shipment (tons) & 27,097 & 1,953 \\
\cline { 2 - 4 } & freightage (NTD/kg) & 67.2 & 71.8 \\
\cline { 2 - 4 } & profits (NTD) & $236,438,740$ & $141,472,924$ \\
\hline \multirow{3}{*}{ Northwest } & shipment (tons) & 9,398 & 839 \\
\cline { 2 - 4 } & freightage (NTD/kg) & 55.1 & 63.6 \\
\cline { 2 - 4 } & profits (NTD) & $-29,830,485$ & $55,448,564$ \\
\hline
\end{tabular}

smallest capacity. Table 9 shows that Northwest Airline has slightly cheaper fair rate but much longer delivery time than its opponents. And that might be the reason why Northwest received the lowest scores in the rating of service quality. Table 9 also shows the weekly passenger flights which may carry priority cargo.

Given the payoff function derived from Tables 5 and 6 , we solve the market equilibrium problem by applying software MATHEMATICA developed by Varian [15] and produced Tables 10 and 11. From these two Tables we learned that the freightage for the high-volume forwarders is about $5 \%$ cheaper than the one for the medium-to-low-volume forwarders.

This is consistent with the fact that high-volume forwarders often have more bargaining power than their competitors. Nevertheless, the fare rates of all carriers are about 5\% lower 
Table 12. Optimal weekly frequency and the costs for CAL cargo flights (the costs of Table 8 are shown in parentheses).

\begin{tabular}{|c|c|c|c|}
\hline scenario & route & $\begin{array}{c}\text { Weekly } \\
\text { frequency }\end{array}$ & $\begin{array}{c}\text { weekly } \\
\text { costs }\end{array}$ \\
\hline \multirow{5}{*}{$\begin{array}{l}\text { case } 1: \\
\text { some flights } \\
\text { are direct }\end{array}$} & TPE - NRT - ANC - LAX & 1 & \multirow{5}{*}{$\begin{array}{r}47,094,324 \\
(47,102,113\end{array}$} \\
\hline & TPE - ANC - LAX & 1 & \\
\hline & TPE - ANC - SFO & 1 & \\
\hline & TPE - ANC - SFO -LAX & 1 & \\
\hline & TPE - LAX & 4 & \\
\hline \multirow{4}{*}{$\begin{array}{l}\text { case } 2 \text { : } \\
\text { all flights } \\
\text { are transfer }\end{array}$} & TPE - NRT - ANC & 1 & \multirow{4}{*}{$\begin{array}{r}45,483,137 \\
(47,102,113)\end{array}$} \\
\hline & TPE - ANC - SFO -LAX & 1 & \\
\hline & TPE - ANC - SFO & 1 & \\
\hline & TPE - ANC - LAX & 5 & \\
\hline
\end{tabular}

Table 13. Optimal weekly frequency and the costs for EVA cargo flights (the costs of Table 8 are shown in parentheses).

\begin{tabular}{|c|c|c|c|}
\hline scenario & route & $\begin{array}{l}\text { weekly } \\
\text { frequency }\end{array}$ & $\begin{array}{c}\text { weekly } \\
\text { costs }\end{array}$ \\
\hline \multirow{5}{*}{$\begin{array}{l}\text { case 1: } \\
\text { some flights } \\
\text { are direct }\end{array}$} & TPE - NRT - ANC - LAX & 1 & \multirow{5}{*}{$\begin{array}{c}42,506,580 \\
(39,132,037)\end{array}$} \\
\hline & TPE - ANC - LAX & 1 & \\
\hline & TPE - ANC - SFO & 1 & \\
\hline & TPE - ANC - SFO - LAX & 1 & \\
\hline & TPE - LAX & 6 & \\
\hline \multirow{5}{*}{$\begin{array}{l}\text { case } 2: \\
\text { all flights } \\
\text { are transfer }\end{array}$} & TPE - NRT - ANC & 1 & \multirow{5}{*}{$\begin{array}{c}41,952,396 \\
(39,132,037)\end{array}$} \\
\hline & TPE - NRT - ANC - SFO & 1 & \\
\hline & TPE - ANC - SFO - LAX & 1 & \\
\hline & TPE - ANC - SFO & 1 & \\
\hline & TPE - ANC - LAX & 6 & \\
\hline
\end{tabular}

than the existing freightage structure. The results imply that carriers can offer more discounts to forwarders with higher demand to attract more forwards and increase revenues. Meanwhile, CAL would have the largest share and the highest freightage in the market for both ordinary and priority cargo. And that is consistent with the fact that CAL, who has the largest shipping capacity, is the leader of the market.

Tables 12 and 13 show the adjusted schedules of cargo flights for CAL and EVA ${ }^{1}$. Due to the limitation of our access to costs data, we could only consider the outbound operation costs for domestic airlines in the case study. Additionally, some of the flights between TPE and LAX remain direct in case 1 while none of direct flights exists in case 2. By comparing Tables 8, 12, and 13 we learned that in case 1 , CAL should extend the route of TPE - NRT - ANC to cover LAX, and should drop by SFO in one of the flights that covers

${ }^{1}$ Given the fact that we do not have access to the cost data of Northwest Airlines, we assume the schedules of Northwest remain unchanged.
Table 14. Comparison of carriers' annual profits in NTD under various scenarios (Case 0 for existing schedule).

\begin{tabular}{|c|r|r|r|}
\hline scenario & \multicolumn{1}{|c|}{ case 0} & \multicolumn{1}{c|}{ case 1} & \multicolumn{1}{c|}{ case 2} \\
\hline CAL & $563,309,059$ & $442,933,083$ & $426,295,619$ \\
\hline EVA & $382,626,026$ & $644,361,109$ & $624,126,414$ \\
\hline Northwest & $28,189,346$ & $8,276,443$ & $29,432,920$ \\
\hline
\end{tabular}

the route of TPE - ANC - LAX. On the other hand, EVA should not only adopt the changes in CAL's routes but also add 2 weekly direct flights from Taipei to Los Angles.

Similarly, the schedule changes in case 2 include converting all CAL's direct weekly flights between TPE and LAX to drop by ANC for 3 flights and to drop by ANC and SFO for one flight. As for EVA's schedule, the adjustment is about the same as in CAL, except that one of the direct flights between TPE and LAX has been replaced by a new route, i.e., TPE NRT - ANC - SFO. With the provision of transfer flights in case 2, CAL and EVA could reduce their operating cost by $3.4 \%$ and $1.3 \%$, respectively.

Notably as shown in Table 14, we learned that although Case 2 offers the lowest operating cost among all scenarios, it is Case 1 that yields the maximum profit for EVA, the leading carriers in the market. On the other hand, neither CAL nor Northwest could garner more profits under Case 1 scenario in comparison with Case 0. In other words, in the oligopolistic market, it is very likely that the leader would not only have the largest share, but also earn much more profit than its opponents.

\section{CONCLUSION}

The major findings of our study are as follows:

1. According to the shipping demand model, forwarders are more sensitive to freightage, delivery time, and frequency than to service quality.

2. The optimal freightage for high-volume forwarders (MVF) is about $5 \%$ cheaper than that for the medium-to-lowvolume forwarders (MLVF). And the optimal fare rates of all carriers are about 5 percent lower than the existing freightage structure. In other words, our results suggest that carriers can offer more discounts to forwarders with higher demand to attract more forwards and increase revenues.

3. The leader of air carriers would have not only the largest share, but also the highest freightage for both ordinary and priority cargo. As a result, the leader would garner more profit than its opponents.

4. The adjusted flight schedule shows that carriers could further reduce their operating cost by $1 \%$ to $3 \%$ with the provision of transfer flights.

To extend the scope and the application of our study, we suggest the following directions for future research: 
1. The service network of air cargo carriers from Taiwan should be expanded to include the entire continent of North America.

2. A more efficient algorithm is needed to deal with the scheduling problem of the expanded network with variable demand.

3. Code sharing and other forms of airline alliances should be integrated into the pricing and scheduling of air cargo market.

Namely, with the ever increasing capacity of computing power, our approach is an effective way to incorporate oligopolistic competition behavior into the scheduling problem of cargo flights. On the other hand, our limitation in data acquisition prevents us from analyzing the market in greater detail. We suggest that if the cost data of all carriers in the market were available, the development of a more comprehensive example in the future study would be necessary.

\section{REFERENCES}

1. Ben-Akiva, M. and Lerman, S., Discrete Choice Analysis, MIT Press, Cambridge, Massachusetts (1985).

2. Bowen, J. and Leinbach, T., "Market concentration in the air freight forwarding industry," Tijdschrift voor Economische en Sociale Geografie, Vol. 95, No. 2, pp. 74-188 (2004).

3. Hansen, M., "Airline competition in a hub-dominated environment: an application of non-cooperative game theory," Transportation Research B, Vol. 24, No. 1, pp. 27-43 (1990).

4. Lee, Y. L., A Competition Model of Air Cargo Carriers: A NonCooperative Game Approach, Master Thesis, Department of Transportation Management, Tamkang University, Taiwan (2004).

5. Lenormand, D., "Market trend in the air freight industry- a Chinese air cargo industry perspective," Business Report for Airbus, pp. 1-5 (2004).

6. Nicole, A., "Competition in a deregulated air transportation market,"
Operational Research, Vol. 129, pp. 337-345 (2001)

7. Oum, T. H. and Yu, C. Y., "Cost competitiveness of major airlines: an international comparison," Transportation Research A, Vol. 32, No. 6, pp 407-422 (1998).

8. Owen, G., Game Theory -Second Edition, Academic Press Inc., Orlando, Florida (1982).

9. Park, Y., Choi, J. K., and Zhang, A., "Evaluating competitiveness of air cargo express services," Transportation Research Part E, Vol. 45, pp. 321-334 (2009).

10. Shyr, O. F. and Chang, L., "An effectiveness assessment of code-sharing practices among airlines: A cooperative game approach," Transportation Planning Journal, Vol. 32, No. 4, pp. 601-630 (2003).

11. Shyr, O. F. and Hung, M., "Intermodal competition with high speed rail A game theory approach," Journal of Marine Science and TechnologyTaiwan, Vol. 18, No. 1, pp. 32-40 (2010).

12. Shyr, O. F. and Kuo, Y., "Applying TOPSIS and cooperative game theory in airline coalition decisions," Journal of Marine Science and Technology-Taiwan, Vol. 16, No. 1, pp. 8-18 (2008).

13. Smith, L. D., Campbell, J. F., and Mundy, R., "Modeling net rates for expedited freight services," Transportation Research Part E: Logistics and Transportation Review, Vol. 43, No. 2, pp. 192-207 (2007).

14. Tang, C.-H., Yan, S., and Chen, Y.-H., "An integrated model and solution algorithms for passenger, cargo, and combi flight scheduling," Transportation Research Part E, Vol. 44, pp. 1004-1024 (2008).

15. Varian, H., Economic and Financial Modeling with MATHEMATICA, Springer-Verlag Publishers, the Electronic Library of Science, Santa Clara, California (1993).

16. Xiao, F. and Yang, H., "Three-player game-theoretic model over a freight transportation network," Transportation Research Part C: Emerging Technologies, Vol. 15, No. 4, pp. 209-217 (2007).

17. Yan, S., Chen, S. C., and Chen, C. H., "Air cargo fleet routing and timetable setting with multiple on-time demands," Transportation Research Part E, Vol. 42, pp. 409-430 (2006).

18. Zhang, A., Lang, C., Hui, Y. V., and Leung, L., "Intermodal alliance and rivalry of transport chains: The air cargo market," Transportation Research Part E, Vol. 43, pp. 234-246 (2007).

19. Zhang, A. and Zhang, Y., "A model of air cargo liberalization: passenger vs. all-cargo carriers," Transportation Research Part E, Vol. 38, pp. 175-191 (2002). 